\title{
Complications of thoracic surgery: post-pneumonectomy bronchopleural fistula
}

\author{
Anuj Wali ${ }^{1}$, Andrea Billè ${ }^{1,2}$ \\ ${ }^{1}$ Thoracic Surgery Department, Guy's Hospital, London, UK; ${ }^{2}$ Division of Cancer Studies, King's College London Faculty of Life Sciences \& \\ Medicine at Guy's, Kings College and St. Thomas' Hospitals, London, UK \\ Contributions: (I) Conception and design: All authors; (II) Administrative support: A Billè; (III) Provision of study materials or patients: A Wali; (IV) \\ Collection and assembly of data: A Wali; (V) Data analysis and interpretation: A Wali; (VI) Manuscript writing: All authors; (VII) Final approval of \\ manuscript: All authors. \\ Correspondence to: Andrea Billè. Thoracic Surgery Department, Guy's Hospital, $6^{\text {th }}$ Floor, Borough Wing, London SE1 9RT, UK. \\ Email: andrea.bille@gstt.nhs.uk.
}

\begin{abstract}
Bronchopleural fistula (BPF) describes an abnormal connection between a bronchus (main, lobar or segmental) and the pleural cavity. BPF is a recognized complication after pneumonectomy and is associated with significant morbidity and mortality. The risk of post-pneumonectomy BPF (PP-BPF) is greater in right sided operations, male patients, residual tumor, barotrauma, previous TB and active infection. If suspected, diagnosis of BPF should be made expeditiously with computed tomography scanning and bronchoscopy. The management depends on the timing of presentation, the size of the fistula and the clinical status of the patient. All patients require drainage of the infected pleural space and intravenous antibiotics. In early presentations, re-do thoracotomy followed by stump closure and reinforcement with a pedicled muscle flap is recommended. If the fistula is small $(<5 \mathrm{~mm})$ or the patient is not fit enough for major surgery, bronchoscopic repair using fibrin glue application, stents or closure devices can be attempted. Minimally invasive techniques can also be used as a temporizing measure while optimizing a patient for a major intervention. There are multiple case reports describing novel bronchoscopic techniques for management of BPF. The risk of BPF should be reduced in high-risk patient groups by implementing bronchial stump coverage (BSC) at the time of pneumonectomy. Overall, the literature is limited by the relative rarity of the problem. Much of the literature is based on retrospective studies and case series which leads to inherent biases preventing true comparative studies in operative techniques and outcomes. Metaanalysis of case reports and new randomized controlled trials may give more evidence to support the current findings. While some simple principles should be followed, management of BPF needs to be individualized to each patient's clinical picture.
\end{abstract}

Keywords: Pneumonectomy; post-pneumonectomy bronchopleural fistula (PP-BPF); bronchial stump coverage (BSC); post-pneumonectomy empyema (PPE)

Received: 19 February 2020; Accepted: 26 March 2020; Published: 10 January 2021.

doi: $10.21037 /$ shc. 2020.03 .02

View this article at: http://dx.doi.org/10.21037/shc.2020.03.02

\section{Introduction}

Evarts A. Graham performed the first successful single stage pneumonectomy for lung cancer in 1933; and with the first pneumonectomy came the first post-pneumonectomy bronchopleural fistula (PP-BPF) (1). BPF describes an abnormal connection between a bronchus (main, lobar or segmental) and the pleural cavity. This can occur for many reasons and most commonly is as a complication of lung resection; however, BPF can also be a sequela of necrotic infection, persistent spontaneous pneumothorax and chemotherapy or radiotherapy for malignancy. BPF 


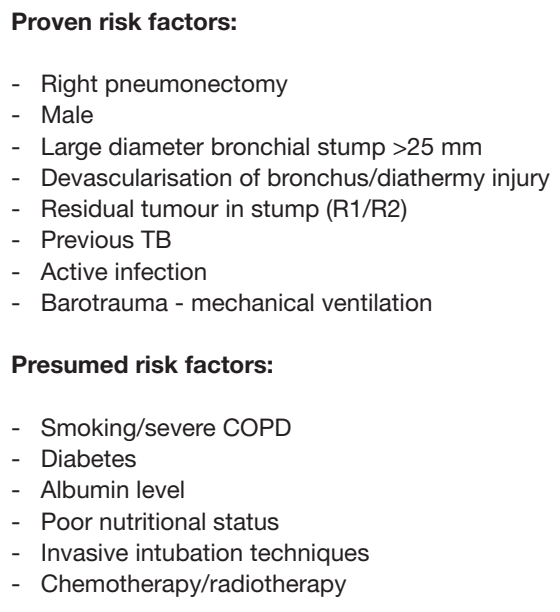

Figure 1 Proposed prognostic factors for BPF postpneumonectomy. BPF, bronchopleural fistula.

in any instance is associated with significant morbidity and mortality but it is particularly catastrophic in the setting of a pneumonectomy owing to the lack of pulmonary reserve in this patient group. Pneumonectomy has the highest mortality rate of all lung resections. Recent studies report a 30-day mortality rate of around $5.4 \%$ and the British Thoracic Society recommends a mortality rate of $<8 \%(2,3)$.

Incidence rates of BPF after pneumonectomy have reduced due to improved surgical and perioperative management of patients. Recent studies suggest that they occur in as many as $6.3 \%$ of all pneumonectomy operations (4). $\mathrm{PP}-\mathrm{BPF}$ is known to carry a high mortality rate ranging from $21 \%$ to $71 \%$ due to the risk of infection of the pneumonectomy space and contralateral pneumonia (5).

Despite the relatively high-risk of BPF in the setting of pneumonectomy and the significant morbidity and mortality associated, there is still no consensus regarding the risk factors, prevention and management of PP-BPF. This review aims to assess the current literature and present the best management of PP-BPF in the modern setting.

\section{Aetiology}

There are many hypotheses regarding the risk factors that confer a higher risk of PP-BPF, however, there are relatively few studies formally assessing the prognostic factors for bronchopleural fistula after pneumonectomy. Figure 1 summarizes the often-quoted causes however the evidence behind many of them is still controversial.

The vast majority (95\%) of pneumonectomy operations

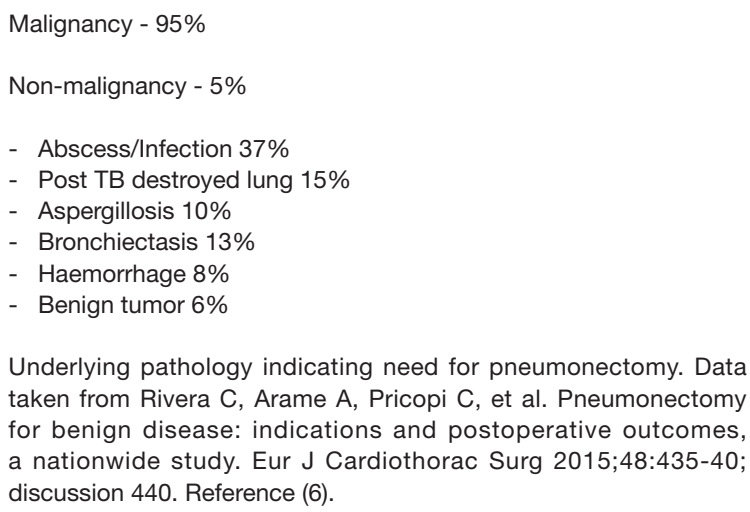

Underlying pathology indicating need for pneumonectomy. Data taken from Rivera C, Arame A, Pricopi C, et al. Pneumonectomy for benign disease: indications and postoperative outcomes, a nationwide study. Eur J Cardiothorac Surg 2015;48:435-40; discussion 440. Reference (6).

Figure 2 Reasons for pneumonectomy.

are performed for malignancy (Figure 2) and as a result most of the papers describing risk factors for PP-BPF refer to cancer related factors (6). The indication for pneumonectomy doesn't seem to impact significantly on rates of PP-BPF. Studies report a similar incidence (5.1-6.9\%) of BPF between malignant and non-malignant indications for pneumonectomy (7-9). Although, it should be noted that the overall risk of morbidity and mortality after PP-BPF in the benign disease group is significantly higher than for malignant indications (6). This is attributed to the likelihood that these are salvage operations in septic patients with acute presentations and poorer functional status.

$\mathrm{BPF}$ is more common after pneumonectomy than lobar or sublobar resections $(10,11)$. This is purported to be as a result of the loss of the protective effects of the remaining lung parenchyma abutting the bronchial stump. Furthermore, a pneumonectomy requires a more extensive hilar dissection which can compromise bronchial vascular supply which in turn increases the risk of ischemia and necrosis. Similarly, Right pneumonectomy is a major risk factor for PP-BPF as the stump is more exposed than the left sided operation $(12,13)$. Gursoy and colleagues summarized a number of case series and quote the incidence of BPF is between $0 \%$ and $6.3 \%$ after left pneumonectomy, but between $1.1 \%$ and $22.9 \%$ after right pneumonectomy (14). One explanation for this difference lies in the anatomical variation between left and right. After left sided pneumonectomy, the left main bronchus sits within the mediastinum buttressed by the arch of the aorta and the left pulmonary artery. On the right side there is no such anatomical protection and therefore the stump is more vulnerable to fistula formation. This suggests that 
some sort of bronchial stump coverage (BSC) at the time of pneumonectomy may be beneficial in prevention of $\mathrm{PP}$ BPF.

Early anatomical studies of the bronchi have demonstrated that there are almost always two bronchial arteries supplying the left side, but there is only one artery on the right side (which is derived from a shared origin with the intercostal artery) (15). Therefore, the right bronchial stump is more susceptible to devascularization from dissection, inflammation and infective processes.

The diameter of the main bronchus may also contribute to the increased risk of BPF. The right main bronchus is known to be on average larger than the left which may explain the increased rates of right sided PP-BPF (16). Men have been shown to have larger bronchi compared to women and multiple studies correlate that men are also more likely to suffer from BPF post lung resection (16). The bronchus is inherently designed to remain open due to its cartilaginous rings and the increased tension that a larger bronchus would confer on closure is a compelling argument to explain this direct relationship between bronchial diameter and BPF.

Compliance of the bronchus and its surrounding structures is a recurring theme in the literature. The less healthy and malleable the tissues, the more likely that the closure will reopen. This explains why infectious conditions carry at higher risk of BPF. Pre-operative empyema significantly increases risk of BPF (17). Furthermore, previous infection with tuberculosis at any point increases chances of PP-BPF (14). An already damaged and fibrotic bronchus/surrounding lung would understandably undermine any attempts at closure. Residual tumor in stump also confers an increased risk of BPF (18). Whilst also being oncologically inadequate, the residual inflammatory carcinomatous tissue disrupts the healing of the suture line.

Multiple retrospective cohort studies demonstrate a significant risk of $\mathrm{PPBPF}$ in patients who require mechanical ventilation in the postoperative period (19). Unfortunately, reasons for post-operative ventilation are mostly unavoidable. Unfortunately, data across these studies is not standardized, meaning that there is likely a large discrepancy in ventilation parameters between each patient. Therefore, guidance for mechanical ventilation pressures is limited. Early extubation and cautious ventilation pressures in cases of re-intubation are recommended in line with this report's findings.

There are multiple other generalized surgical risk factors that should also be assessed and managed perioperatively (Figure 2) $(10,11,20,21)$. The principal issue with risk factor analysis for PP-BPF is that pneumonectomy is rare and therefore the numbers of PP-BPF are few. This means that there is a lack of consistency in surgical approaches between different surgeons; which, in turn, hampers meaningful comparative studies.

\section{Management}

The optimal management for PP-BPF is still debated. Paramount to successful management of PP-BPF is early recognition followed by planned and measured multidisciplinary care.

Reduction of fluid level on imaging, contralateral aspiration pneumonitis and expectorating serosanguinous fluid are pathognomic for the condition. PP-BPF most commonly presents with raised inflammatory markers as a result of an infected pleural space leading to postpneumonectomy empyema (PPE). This manifests with reduced oxygen saturations, productive cough, surgical emphysema and a sepsis.

The timing of diagnosis is crucial in deciding the management options for the patient. Early PP$\mathrm{BPF}$ is described as occurring within 30 days of the pneumonectomy and is related to technical issues with the procedure. It is thought that early PP-BPF is amenable to redo-thoracotomy, direct repair of the defect, reinforcement and closure. In late PP-BPF, there has likely been a subacute infective process that contributes to a hostile space; and therefore, a staged approach may be more appropriate to control the infected space.

Overall, the management of BPF with infected space reflects the management of empyema. Clagett in 1963 (22) demonstrated that PPE with or without BPF could be successfully treated by open pleural drainage, packing of the pleural space, dressing changes, and, when the thorax was sterile, secondary chest wall closure with obliteration of the pleural cavity with an antibiotic solution. Modern approaches still use the above principles in management but there has been a move towards minimally invasive techniques and a focus on bronchial stump closure when appropriate.

The general principles of PP-BPF management are intravenous antibiotics with immediate drainage of the infected pleural space; closure and reinforcement of the $\mathrm{BPF}$ if appropriate and finally obliteration of the pleural cavity (5). 


\section{Drainage of pleural space}

Once PPE has been diagnosed, early management of infection is mandatory. Immediate intravenous antibiotic cover and drainage of the pleural space is essential. The pleural space must be emergently drained because aspiration of the pleural contents through the BPF defect into the contralateral lung is associated with development of acute respiratory distress syndrome. This is a major cause of immediate morbidity and mortality for patients with untreated PPE with PP-BPF (23). Options for drainage of the space include tube thoracostomy, VATS washout and open window thoracostomy (OWT). In acute presentation of PP-BPF chest drain insertion should be used to evacuate the space. For long-term space management, Clagett's eponymous procedure has been widely accepted as the standard of care for PP-BPF. Initially, the main failure of Clagett's approach was due to a persistent or recurrent fistula and thus there is now a focus on PP-BPF stump closure techniques (24). Open closure techniques are suitable for bigger PP-BPF ( $>5 \mathrm{~mm}$ ) and involve direct closure of the bronchial stump with reinforcement using a surrounding structure. There is a shift towards investigating minimally invasive techniques for smaller PP-BPF $(<5 \mathrm{~mm})$, however, not all PP-BPF are amenable to these endoscopic techniques and will require open repair.

\section{Open BPF closure}

Pragmatic clinical assessment of each patient should guide the decision for open repair $v s$. minimally invasive techniques. Important factors include the patient condition, early $v$ s. late PP-BPF, size of the BPF, length of the residual bronchial stump, any previous attempts at closure and the patient's wishes.

Therefore, we recommend early imaging (CT) and bronchoscopy to assess for size of BPF and stump parameters that will guide management. If the patient is well enough and not septic, the PP-BPF is large $(>0.5 \mathrm{~mm})$ and the stump long enough, then open repair through thoracotomy/sternotomy should be attempted.

Once open surgery is attempted, the surgeon needs to directly assess the stump. Cautious dissection near mediastinal structures is required and care not to devascularize the remaining blood supply of the bronchial stump. If the stump is long, it can debride back to healthy tissue and then closure of the bronchus attempted. No difference has been found between hand suture or staple gun for bronchus closure and so the surgeon's preference is acceptable (25).

The initial repair should then be buttressed with a wellvascularized pedicled tissue which confers extra protection to the repaired defect. The literature reports many tissues used for this purpose: Intercostal muscles, pleura, pericardial fat, extrathoracic muscle (26), omentum (27), or diaphragm flap (28). More recently matrix seeded with autologous mesenchymal stem cells (MSCs) have been trialled (29). Another benefit of large muscle transposition into the thoracic space is that it helps with obliteration of the pleural space which is essential after repair and closure.

Muscles associated with the thoracic cage are most easily harvested and sited due to the locality of the tissues e.g., intercostals, serratus anterior, latissimus dorsi. Puskas and colleagues' series of PP-BPF repairs reported a $92 \%$ success rate of first-time repair with omentum patch, $64 \%$ success with muscle repair and $0 \%$ with pleural flaps (30). Their results suggest that omentum repair is superior to muscle and pleural flaps in PP-BPF. Other studies report no longterm failures of stump reinforcement with muscle repair, although the methodologies are unclear (31). It is purported that the omentum's natural ability to migrate to areas of inflammation and induce angiogenesis help with the closure of any persistent BPF. While omental flap repair confers the highest success rate with PP-BPF closure, it does require a further abdominal operation and may not be suitable for all patients.

A transpericardial approach to open repair in PP-BPF is indicated in patients assessed as having short bronchial stumps, or in patients with a hostile thoracic cavity (late presenting PP-BPF with PPE or in those that have had multiple previous procedures). A transpericardial approach allows for access to the most proximal portions of the bronchi and carina through previously unaffected tissue planes that are free from inflammation and adhesions. This technique avoids repeated dissection of friable tissues and avoids disruption of prior indwelling muscle/omental flaps. Outcomes from several case series using the transpericardial approach show respectable outcomes with BPF recurrence of $16 \%$ and mortality of $15 \%$ (5).

There is no review that fully compares the outcomes of each approach and the tissue selected for open repair of PP-BPF. We recommend that each case is unique and that all factors should be considered before deciding on which flap to use. There is currently a gap in the literature for a systematic review of open PP-BPF closure methods and their success rates. 


\section{Minimal access BPF closure}

Endoscopic approaches are of interest to the surgeon as they can be used for small PP-BPF and in those unfit for re-do thoracotomy. They are less invasive and avoid the inherent risks in a second major operation in a high-risk population. Endoscopic approaches include tracheobronchial stenting, closure devices (Amplatzer), glue occlusion and Induction of scarring for closure (YAG laser or injection of sclerosant). One review reports an overall $30 \%$ closure rate using a range of bronchoscopic techniques in a series of studies (32). However, the mortality rate was $40 \%$, much higher than seen in open procedures. This may just reflect the highrisk patient demographic unfit for open closure who were selected for these procedures (32).

Hollaus and colleagues (33) reported injection of fibrin glue into the lumen if the PP-BPF was less than $3 \mathrm{~mm}$. In 9 cases they report cure with fibrin glue therapy alone although there was a high rate $(35.7 \%)$ of requiring salvage surgery (thoracoplasty or OWT). The successful cases were in very small BPF measuring an average of $1 \mathrm{~mm}$ and they report it took 1-3 applications of fibrin glue. It is possible to dislodge and expectorate fibrin glue clots, so the authors recommend injecting the glue into the mucosa if the BPF is larger than $3 \mathrm{~mm}$. Further case series report varied success rates using Cyanoacrolate glue and BioGlue (34-36). Although there are only limited case series, bronchoscopic glue application seems to offer a viable treatment in very small fistula in debilitated patients who are poor surgical candidates. CT guidance has been proposed as another minimally invasive technique to insert transthoracic coils at the site of PP-BPF which act as a scaffold for cyanoacrylate glue application (37). The coils are purported to reduce the incidence of glue displacement.

MSC therapy offers a novel approach to BPF closure. Once implanted, MSCs interact with the environment, promoting tissue healing and regeneration (38). Autologous Bone Marrow derived MSCs have been successfully transplanted bronchoscopically to treat PP-BPF. After 60 days, a full closure of the $3 \mathrm{~mm}$ defect was seen. A subsequent tissue biopsy of the closure demonstrated respiratory epithelia and a well-defined layer of basal cells and basal-cell hyperplasia consistent with autologous healing (39).

Endobronchial stents have been successfully used for management of larger ( $>5 \mathrm{~mm}$ ) PP-BPF (40-42). There are risks of stent migration or erosion and the use of an atrial septal closure device has been proposed as a fixed alternative to simple stenting $(43,44)$. While useful in large BPFs there are inherent problems of introducing a foreign body to the bronchus: excessive reactive tissue formation at the stent edges and inefficient clearance of secretions (due to the loss of the muco-ciliary escalator) have been postulated to lead to infections and breakdown of stump.

It should again be emphasized that these approaches for endoscopic closure of BPFs must be coupled with control of the associated pleural infection through a combination of parenteral antibiotic use, tube thoracostomy drainage, VATS debridement and instillation of antibiotic fluids into the pleural space. In general, endoscopic techniques are of particular use in patients too unfit for surgery, those with a small PP-BPF and as a bridging therapy for patients who have chronically infected spaces while they are optimized for definitive surgical management.

\section{Management of space}

After satisfactory repair of the defect it is essential to manage the space left behind after drainage of the pleural space to avoid infection and maintain an environment that promotes healing and normal physiology. Both endoscopic and open repairs of PP-BPF are amenable to instillation of antibiotic solutions in order to fill and sterilize the pleural space. This may be done alongside tube thoracostomy to allow for repeated instillation of fluid. This remains the most commonly used method of pleural space management and is generally deemed low risk and effective in sterilization of the cavity.

Povidone-iodine or antibiotic soaked towels are used to fill the pleural space in the Clagett's procedure. These towels are changed regularly until adequate sterilisation allows for closure of the OWT. This protracted process requires long hospital stays and multiple procedures. Peretti and colleagues proposed a vacuum assisted closure (VAC) device to expedite the healing process associated with OWT. Infection control and successful chest cavity closure was achieved in all surviving patients $(45,46)$. There is good evidence that VAC closure devices improve healing through removal of bacteria, optimization of blood flow, decrease in tissue oedema, and removes excessive fluid from the wound bed (47). Care must be made to ensure that careful packing ensures that there is no direct negative pressure on mediastinal structures.

In order to avoid OWT, which can be distressing for patients, an accelerated closed-chest wall VAC assisted protocol was suggested by Schneiter and colleagues (48). 
Their method involves repair and reinforcement of PP$\mathrm{BPF}$ at the first procedure, temporary chest wall closure followed by regular repeated opening and closing of the thoracotomy to allow for changes of povidone-iodine soaked towels. Chest drains with negative pressure are left in the pleural space between the towels and the chest wall in order to facilitate the VAC effects between towel changes. They report that definitive chest closure was achieved within 8 days for $94.7 \%$ of patients and an overall success rate of $97.3 \%$ (with a median hospital stay of 18 days). This method offers the benefits of repeated VAC-assisted pleural sterilization whilst maintaining chest wall integrity throughout. They report that patients were able to mobilize between procedures and early chest closure facilitates shorter lengths of hospital stay. The psychological impact of maintaining chest wall integrity in the recovery process should not be underestimated.

Post-pneumonectomy syndrome describes the range of physiological changes that occur when the mediastinum shifts towards the empty cavity after removal of the lung (49). This rare complication can result in obstruction of the trachea, esophagus and great vessels. Large muscle transposition associated with the modified Clagett's procedure also helps to fill the post-pneumonectomy space which in turn reduces the likelihood of mediastinal shift. There has been successful use of saline implants to fill the PP-BPF space with post-pneumonectomy syndrome (50). In this setting, subclinical infection must be ruled out to prevent infection of the implant and ensure its longevity. Thoracoplasty remains a last resort procedure to obliterate the chest space in chronically infected and difficult to manage patients.

\section{Prevention}

The mainstay of preventative techniques for PP-BPF are related to identifying the high-risk patients and reducing their risk using operative techniques. Right sided pneumonectomy, large diameter bronchi, male patient and a pre-operative infected space are all non-modifiable risk factors for PP-BPF and cannot be managed pre-operatively. High-risk patients should therefore receive intraoperative BSC at the time of pneumonectomy. BSC utilizes one of many local structures to reinforce the resected stump in order to prevent future BPF. This can be a flap from pericardial fat, pericardium, parietal pleura or intercostal muscle.

A meta-analysis of 3,879 patients assessing the success rate of BSC suggested no significant difference in outcomes between stump coverage and no stump coverage (4). Counter-intuitively the BSC group had a higher average rate of PP-BPF (6.3\% BSC vs. $4.0 \%$ no BSC). Unfortunately, this data is misleading, as the majority of studies were not randomized. The current surgical practice of implementing BSC in higher risk patients more susceptible to fistula formation means there is a considerable selection bias in the data. There is one randomized trial in the literature of 70 patients who were randomized at the time of pneumonectomy to either receive or not receive BSC. The group that received an intercostal muscle flap BSC had a significantly lower incidence of $\mathrm{BPF}$ development $(0 \% v s$. $8.8 \%)$ and PPE (0\% vs. $7.4 \%)$ compared with the group that received conventional pneumonectomy (51).

We suggest that all right sided pneumonectomy and those with higher risk profiles should undergo muscle flap BSC. The intercostal muscle is a well vascularised muscle flap that offers good outcomes at both time of pneumonectomy (51) and when used for PP-BPF closure (30); whilst being technically less challenging to harvest and transpose than other options.

In the perioperative setting it is important to manage all well-known risk factors for surgical complications. These well documented modifiable risk factors in surgery (such as smoking, diabetes, steroid use, poor nutrition etc.) have not been isolated in univariate/multivariate analysis for PP-BPF. However, it cannot be denied that it is prudent to optimise all patient variables undergoing a major operation in order to reduce risk of PP-BPF. In the post-operative period, the major risk factor for PP-BPF is mechanical ventilation. This can be avoided by ensuring adequate analgesia and early mobilisation to prevent respiratory failure requiring intubation. Alongside this, good nutrition, glycaemic control and early management of infections contribute to improved recovery post-pneumonectomy.

\section{Conclusions}

The literature describing PP-BPF and its management is limited by the rarity and severity of the condition. This means that much of the evidence for their management relies on case series and expert opinion. Currently, studies investigating $\mathrm{PP}-\mathrm{BPF}$ have too many patient variables and surgical management options which means that truly comparative studies of operative techniques are unavailable. Despite this, there are general management principles 
Management of PP-BPF - summary of techniques with reported success rates in parentheses (taken from references cited in the text if available).

EARLY PP-BPF - $<30$ days post pneumonectomy

\begin{tabular}{|c|c|c|}
\hline & Fit for surgery & Not fit for surgery \\
\hline$<5 \mathrm{~mm} \mathrm{BPF}$ & \multirow[t]{2}{*}{$\begin{array}{l}\text { - Redo Thoracotomy and repair } \\
\text { - Omentum repair (92\%) } \\
\text { - Muscle repair (64\%) }\end{array}$} & $\begin{array}{l}\text { - } \text { Bronchoscopic Glue application (31\%) } \\
\text { - Transthoracic coils and glue } \\
\text { - Stent insertion } \\
\text { - Closure Device (e.g., Amplatzer) }\end{array}$ \\
\hline$\geq 5 \mathrm{~mm} \mathrm{BPF}$ & & $\begin{array}{l}\text { - Stent insertion } \\
\text { - Closure Device (e.g., Amplatzer) }\end{array}$ \\
\hline
\end{tabular}

LATE PP-BPF - $\geq 30$ days post pneumonectomy

\begin{tabular}{|l|l|l|}
\hline & Fit for surgery & Not fit for surgery \\
\hline$<5 \mathrm{~mm} \mathrm{BPF}$ & - Bronchoscopic techniques e.g., Glue application & - Bronchoscopic Glue application (31\%) \\
& $\begin{array}{l}\text { - to close BPF while optimising patient and sterilising pleural space } \\
\text { - Redo Thoracotomy and repair }\end{array}$ & $\begin{array}{l}\text { - Transthoracic coils and glue } \\
\text { - Stent insertion }\end{array}$ \\
\hline$\geq 5 \mathrm{~mm} \mathrm{BPF}$ & - Redosure Device (e.g., Amplatzer) \\
& - Sternotomy for transpericardial approach (69\%) & - Stent insertion \\
\hline
\end{tabular}

Figure 3 Management of PP-BPF—summary of techniques with reported success rates in parentheses (taken from references cited in the text if available). PP-BPF, post-pneumonectomy bronchopleural fistula.

that should be followed (Figure 3) and every patient's management should be individualised according to their clinical picture and the surgeon's experience.

\section{Acknowledgments}

Funding: None.

\section{Footnote}

Provenance and Peer Review: This article was commissioned by the Guest Editor (David Waller) for the series "Complications of Thoracic Surgery-Aetiology, Management and Prevention", published in Shangbai Chest. This article has undergone external peer review.

Conflicts of Interest: All authors have completed the ICMJE uniform disclosure form (available at http://dx.doi. org/10.21037/shc.2020.03.02). The series "Complications of Thoracic Surgery-Aetiology, Management and Prevention" was commissioned by the editorial office without any funding or sponsorship. The authors have no other conflicts of interest to declare.

Ethical Statement: The authors are accountable for all aspects of the work in ensuring that questions related to the accuracy or integrity of any part of the work are appropriately investigated and resolved.

Open Access Statement: This is an Open Access article distributed in accordance with the Creative Commons Attribution-NonCommercial-NoDerivs 4.0 International License (CC BY-NC-ND 4.0), which permits the noncommercial replication and distribution of the article with the strict proviso that no changes or edits are made and the original work is properly cited (including links to both the formal publication through the relevant DOI and the license). See: https://creativecommons.org/licenses/by-nc-nd/4.0/.

\section{References}

1. Baue AE. Landmark perspective: Evarts A. Graham and 
the first pneumonectomy. JAMA 1984;251:260-4.

2. Powell ES, Pearce AC, Cook D, et al. UK pneumonectomy outcome study (UKPOS): a prospective observational study of pneumonectomy outcome. J Cardiothorac Surg 2009;4:41.

3. British Thoracic Society; Society of Cardiothoracic Surgeons of Great Britain and Ireland Working Party. BTS guidelines: guidelines on the selection of patients with lung cancer for surgery. Thorax 2001;56:89-108.

4. Di Maio M, Perrone F, Deschamps C, et al. A metaanalysis of the impact of bronchial stump coverage on the risk of bronchopleural fistula after pneumonectomy. Eur J Cardiothorac Surg 2015;48:196-200.

5. Bribriesco A, Patterson GA. Management of postpneumonectomy bronchopleural fistula: from thoracoplasty to transsternal closure. Thorac Surg Clin 2018;28:323-35.

6. Rivera C, Arame A, Pricopi C, et al. Pneumonectomy for benign disease: indications and postoperative outcomes, a nationwide study. Eur J Cardiothorac Surg 2015;48:43540; discussion 440.

7. Li Y, Hu X, Jiang G, et al. Pneumonectomy for treatment of destroyed lung: a retrospective study of 137 patients. Thorac Cardiovasc Surg 2017;65:528-34.

8. Conlan AA, Lukanich JM, Shutz J, et al. Elective pneumonectomy for benign lung disease: modern-day mortality and morbidity. J Thorac Cardiovasc Surg. 1995;110:1118-24.

9. Byun CS, Chung KY, Narm KS, et al. Early and longterm outcomes of pneumonectomy for treating sequelae of pulmonary tuberculosis. Korean J Thorac Cardiovasc Surg 2012;45:110-5.

10. Asamura H, Naruke T, Tsuchiya R, et al. Bronchopleural fistulas associated with lung cancer operations: univariate and multivariate analysis of risk factors, management, and outcome. J Thorac Cardiovasc Surg 1992;104:1456-64.

11. Jichen QV, Chen G, Jiang G, et al. Risk factor comparison and clinical analysis of early and late bronchopleural fistula after non-small cell lung cancer surgery. Ann Thorac Surg 2009;88:1589-93.

12. Darling GE, Abdurahman A, Yi QL, et al. Risk of a right pneumonectomy: Role of bronchopleural fistula. Ann Thorac Surg 2005;79:433-7.

13. Mammana M, Marulli G, Zuin A, et al. Postpneumonectomy bronchopleural fistula: analysis of risk factors and the role of bronchial stump coverage. Surg Today 2020;50:114-22.

14. Gursoy S, Yazgan S, Ucvet A, et al. Postpneumonectomy bronchopleural fistula in non-small cell lung cancer patients: incidence, survival, mortality, and treatment analysis. Surg Today 2018;48:695-702.

15. Cauldwell EW, Siekert RG. The bronchial arteries; an anatomic study of 150 human cadavers. Surg Gynecol Obstet 1948;86:395-412.

16. Hollaus PH, Setinek U, Lax F, et al. Risk factors for bronchopleural fistula after pneumonectomy: stump size does matter. Thorac Cardiovasc Surg 2003;51:162-6.

17. Halezeroglu S, Keles M, Uysal A, et al. Factors affecting postoperative morbidity and mortality in destroyed lung. Ann Thorac Surg 1997;64:1635-8.

18. de Perrot M, Licker M, Robert J, et al. Incidence, risk factors and management of bronchopleural fistulae after pneumonectomy. Scand Cardiovasc J 1999;33:171-4.

19. Toufektzian L, Patris V, Sepsas E, et al. Does postoperative mechanical ventilation predispose to bronchopleural fistula formation in patients undergoing pneumonectomy? Interact Cardiovasc Thorac Surg 2015;21:379-82.

20. Wahi R, McMurtrey MJ, DeCaro LF, et al. Determinants of perioperative morbidity and mortality after pneumonectomy. Ann Thorac Surg 1989;48:33-7.

21. Haraguchi S, Koizumi K, Hioki M, et al. Analysis of risk factors for postpneumonectomy bronchopleural fistulas in patients with lung cancer. J Nippon Med Sch 2006;73:314-9.

22. Clagett OT, Geraci JE. A procedure for the management of postpneumonectomy empyema. J Thorac Cardiovasc Surg 1963;45:141-5.

23. Hollaus PH, Lax F, el-Nashef BB, et al. Natural history of bronchopleural fistula after pneumonectomy: a review of 96 cases. Ann Thorac Surg 1997;63:1391-6; discussion 1396-7.

24. Stafford EG, Clagett OT. Postpneumonectomy emphema. Neomycin instillation and definitive closure. J Thorac Cardiovasc Surg 1972;63:771-5.

25. Graeber GM, Collins JJ Jr, DeShong JL, et al. Are sutures better than staples for closing bronchi and pulmonary vessels? Ann Thorac Surg 1991;51:901-4; discussion 904-5.

26. Arnold PG, Pairolero PC. Intrathoracic muscle flaps: a 10-year experience in the management of life-threatening infections. Plast Reconstr Surg 1989;84:92-8.

27. Stamatis G, Freitag L, Wencker M, et al. Omentopexy and muscle transposition: two alternative methods in the treatment of pleural empyema and mediastinitis. Thorac Cardiovasc Surg 1994;42:225-32.

28. Ahmad U, Chumakova M, Raja S, et al. 
Postpneumonectomy bronchopleural fistula closure with biologic mesh and diaphragm flap. Ann Thorac Surg 2017;104:e215-6.

29. Aho JM, Dietz AB, Radel DJ, et al. Closure of a recurrent bronchopleural fistula using a matrix seeded with patientderived mesenchymal stem cells. Stem Cells Transl Med 2016;5:1375-9.

30. Puskas JD, Mathisen DJ, Grillo HC, et al. Treatment strategies for bronchopleural fistula. J Thorac Cardiovasc Surg 1995;109:989-95; discussion 995-6.

31. Zaheer S, Allen MS, Cassivi SD, et al. Postpneumonectomy empyema: results after the Clagett procedure. Ann Thorac Surg 2006;82:279-86; discussion 286-7.

32. West D, Togo A, Kirk AJ. Are bronchoscopic approaches to post-pneumonectomy bronchopleural fistula an effective alternative to repeat thoracotomy? Interact Cardiovasc Thorac Surg 2007;6:547-50.

33. Hollaus PH, Lax F, Janakiev D, et al. Endoscopic treatment of postoperative bronchopleural fistula: Experience with 45 cases. Ann Thorac Surg 1998;66:923-7.

34. Tsilimigras DI, Antonopoulou A, Ntanasis-Stathopoulos I, et al. The role of BioGlue in thoracic surgery: a systematic review. J Thorac Dis 2017;9:568-76.

35. Scappaticci E, Ardissone F, Ruffini E, et al. Postoperative bronchopleural fistula: endoscopic closure in 12 patients. Ann Thorac Surg 1994;57:119-22.

36. Sabanathan S, Richardson J. Management of postpneumonectomy bronchopleural fistulae. A review. J Cardiovasc Surg (Torino) 1994;35:449-57.

37. Clemson LA, Walser E, Gill A, et al. Transthoracic closure of a postpneumonectomy bronchopleural fistula with coils and cyanoacrylate. Ann Thorac Surg 2006;82:1924-6.

38. Petrella F, Rizzo S, Borri A, et al. Current perspectives in mesenchymal stromal cell therapies for airway tissue defects. Stem Cells Int 2015;2015:746392.

39. Petrella F, Spaggiari L, Acocella F, et al. Airway fistula closure after stem-cell infusion. $\mathrm{N}$ Engl J Med 2015;372:96-7.

40. Andreetti C, D'Andrilli A, Ibrahim M, et al. Effective treatment of post-pneumonectomy bronchopleural fistula by conical fully covered self-expandable stent. Interact

doi: $10.21037 /$ shc.2020.03.02

Cite this article as: Wali A, Billè A. Complications of thoracic surgery: post-pneumonectomy bronchopleural fistula. Shanghai Chest 2021;5:3.
Cardiovasc Thorac Surg 2012;14:420-3.

41. Madden BP, Loke TK, Sheth AC. Do expandable metallic airway stents have a role in the management of patients with benign tracheobronchial disease? Ann Thorac Surg 2006;82:274-8.

42. Kim KH, Lee KH, Won JY, et al. Bronchopleural fistula treatment with use of a bronchial stent-graft occluder. J Vasc Interv Radiol 2006;17:1539-43.

43. Gulkarov I, Paul S, Altorki NK, et al. Use of Amplatzer device for endobronchial closure of bronchopleural fistulas. Interact Cardiovasc Thorac Surg 2009;9:901-2.

44. Billè A, Sabarwhal T, Tom R. Vascular occlusion device closure of bronchial stump fistulae: a straightforward approach to manage bronchial stump breakdown. Gen Thorac Cardiovasc Surg 2012;60:847-50.

45. Perentes J, Abdelnour E, Blatter J, et al. What is the place of the vacuum-assisted closure device in the management of postpneumonectomy empyema?: P127. Respiration 2014;87:554.

46. Perentes JY, Abdelnour-Berchtold E, Blatter J, et al. Vacuum-assisted closure device for the management of infected postpneumonectomy chest cavities. J Thorac Cardiovasc Surg 2015;149:745-50.

47. Venturi ML, Attinger CE, Mesbahi AN, et al. Mechanisms and clinical applications of the vacuum-assisted closure (VAC) device. Am J Clin Dermatol 2005;6:185-94.

48. Schneiter D, Grodzki T, Lardinois D, et al. Accelerated treatment of postpneumonectomy empyema: A binational long-term study. J Thorac Cardiovasc Surg 2008;136:179-85.

49. Adams HD, Junod F, Aberdeen E, et al. Severe airway obstruction caused by mediastinal displacement after right pneumonectomy in a child. A case report. J Thorac Cardiovasc Surg 1972;63:534-9.

50. Yudovich MS, Beal EW, D'Souza DM, et al. Correction of postpneumonectomy syndrome after bronchopleural fistula. J Cardiothorac Surg 2019;14:67.

51. Sfyridis PG, Kapetanakis EI, Baltayiannis NE, et al. Bronchial stump buttressing with an intercostal muscle flap in diabetic patients. Ann Thorac Surg 2007;84:967-71. 